\title{
Design and Development of the Seam Welding of Different Alloys
}

\author{
Prof. Vinod Kumar Manglik, Kohli Sahil, Umat Nikul, Bhavsar Kirtan \\ Professor, Department of Automobile Engineering, Indus Institute of Technology and Engineering, Ahmedabad, Gujarat, India. \\ UG Student, Department of Mechanical Engineering, Indus Institute of Technology and Engineering, \\ Ahmedabad, Gujarat, India.
}

\begin{abstract}
The aim of the project is to design a resistance seam welding machine; resistance seam welding is a process that produces a weld at the faying surfaces of two similar metals. The seam may be a butt joint or an overlap joint and is usually an automated process. It differs from butt welding in that butt welding typically welds the entire joint at once and seam welding forms the weld progressively, starting at one end. Like spot welding, seam welding relies on two electrodes, usually made from copper, to apply pressure and current. The electrodes are disc shaped and rotate as the material passes between them. This allows the electrodes to stay in constant contact with the material to make long continuous welds. The electrodes may also move or assist the movement of the material. A transformer supplies energy to the weld joint in the form of low voltage, high current $\mathrm{AC}$ power. The joint of the work piece has high electrical resistance relative to the rest of the circuit and is heated to its melting point by the current. The semimolten surfaces are pressed together by the welding pressure that creates a fusion bond, resulting in a uniformly welded structure. Most seam welders use water cooling through the electrode, transformer and controller assemblies due to the heat generated. Seam welding produces an extremely durable weld because the joint is forged due to the heat and pressure applied. A properly welded joint formed by resistance welding is typically stronger than the material from which it is formed.
\end{abstract}

\section{Keywords - Welding, Design, Development, Resistance}

\section{INTRODUCTION}

The seam welding process is an adaptation of resistance spot welding and involves making a series of overlapping spot welds by means of rotating copper alloy wheel electrodes to form a continuous leak tight joint. The electrodes are not opened between spots. The electrode wheels apply a constant force to the work pieces and rotate at a controlled speed. The welding current is normally pulsed to give a series of discrete spots, but may be continuous for certain high-speed applications where gaps could otherwise occur between individual spots. Seam welding equipment is normally fixed and the components being welded are manipulated between the wheels. Resistance seam welding is a process that produces a weld at the faying surfaces of two similar metals. The seam may be a butt joint or an overlap joint and is usually an automated process. It differs from butt welding in that butt welding typically welds the entire joint at once and seam welding forms the weld progressively, starting at one end. Like spot welding, seam welding relies on two electrodes, usually made from copper, to apply pressure and current. The electrodes are often disc shaped and rotate as the material passes between them. This allows the electrodes to stay in constant contact with the material to make long continuous welds. The electrodes may also move or assist the movement of the material.

A transformer supplies energy to the weld joint in the form of low voltage, high current AC power. The joint of the work piece has high electrical resistance relative to the rest of the circuit and is heated to its melting point by the current. The semi-molten surfaces are pressed together by the welding pressure that creates a fusion bond, resulting in a uniformly welded structure. Most seam welders use water cooling through the electrode, transformer and controller assemblies due to the heat generated.

Seam welding produces an extremely durable weld because the joint is forged due to the heat and pressure applied. A properly welded joint formed by resistance welding can easily be stronger than the material from which it is formed.

\section{SEAM WELDING PRINCIPLE}

Resistance seam welding (RSW) is a resistance welding process which produces coalescence at the faying surfaces the heat obtained from resistance to electric current through the work parts held together under pressure by electrodes or a type of continuous weld made between or upon overlapping metal parts. The resulting weld is a series of overlapping resistance spot welds made progressively along a joint by rotating the electrodes. Resistance seam welding is another variation on resistance spot welding. In resistance seam welding, the welding electrodes are motor driven wheels rather than stationary caps. This results in a "rolling" resistance weld or seam weld. There are two modes for seam welding: Intermittent and continuous. In intermittent seam welding, the wheels advance to the desired position and stop to make each weld. This process continues until the desired length of the weld is reached. In continuous seam welding, the wheels continue to roll as each weld is made.

\section{TECHNICAL OVER VIEW}

The method used in effect is a continuous spot-welding process in which current is regulated by the timer of the machine. Seam welding consists of a continuous weld on two overlapping pieces of sheet metal that are held together under pressure between two circular electrodes. Coalescence is produced by heat obtained from the resistance tow flow of current that passes through the overlapping sheets. In highspeed seam welding using contiguous current, the frequency of the current acts as an interrupter. The heat at the electrode contact surfaces is kept to a minimum by the use of copper alloy electrodes and is dissipated by flooding the electrodes and weld area with water. Heat generated at the interface by contact resistance is increased by decreasing the electrode 
force. Another variable that influences the magnitude of the heat is the weld time, which in seam welding is controlled by the speed of rotation of the electrodes. The amount of heat generated is decreased with an increase in welding speed.

\section{A. HEATING EQUATIONS}

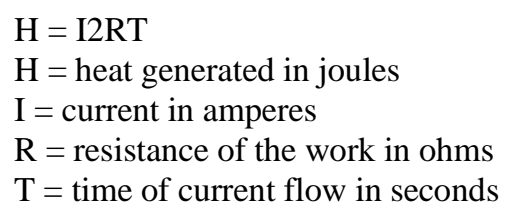

\section{OPERATION OF SEAM WELDING}

The two work pieces to be joined are cleaned to remove dirt, grease and other oxides either chemically or mechanically to obtain a sound weld. The work pieces are overlapped and placed firmly between two wheels shaped copper alloy electrodes, which in turn are connected to a secondary circuit of a step-down transformer. The electrode wheels are driven mechanically in opposite directions with the work pieces passing between them, while at the same time the pressure on the joint is maintained. The overlap of the work piece with its comparatively high electrical resistance is intensely heated by the current. Welding current is passed in series of pulses at proper intervals through the bearing of the roller electrodes wheels. With each positive or negative current half-wave, the parts are heated to a semi-molten condition, especially at the current peaks. As the current passes through the electrodes, to the work piece, heat is generated in the air gap at the point of contact (spot) of the two work pieces. This is heat melts the work pieces locally at the contact point to form a spot weld.

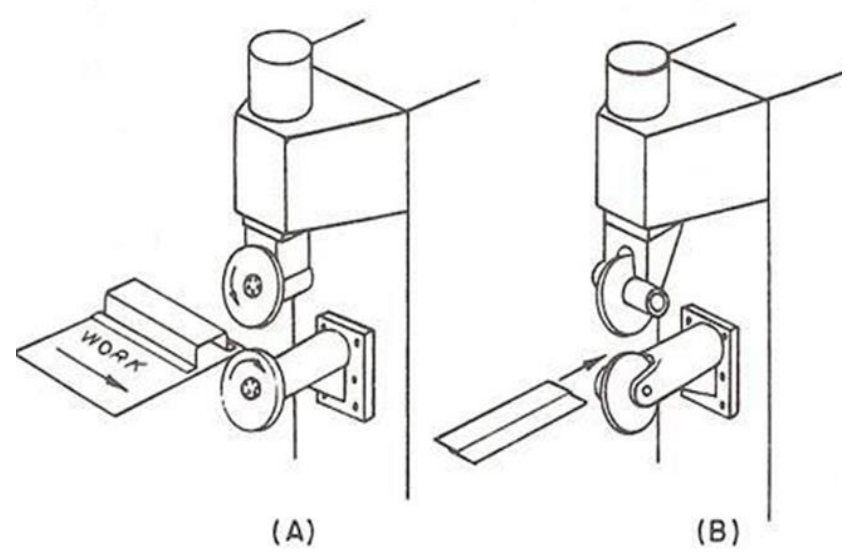

Fig -1: Seam Welding Setup

\section{A. SEAM WELDING}

Under the pressure of continuously rotating electrodes and the current flowing through them, a series of overlapping spot welds are made progressively along the joint. The semimolten overlap surfaces are pressed together by the welding pressure which causes them to bond together into a uniformly welded structure after cooling. Thus, work pieces to be joined are passed through the space between the two discs, and under pressure applied by the discs and current flowing through them, a continuous weld is formed. The weld area is flooded with water to keep the electrode wheels cool during welding. Most seam welded technologies use water cooling through the weld roller assemblies due to the intense heat generated. But overall Seam welding enables high welding speeds to be obtained compared with many other techniques, but can be limited by component shape and wheel access.

\section{B. PARTS USED}

TABLE I

\begin{tabular}{|l|}
\hline Transformer \\
\hline Gear \\
\hline Rod \\
\hline Handle \\
\hline Frame \\
\hline Work Piece Holder \\
\hline Feed for Welding \\
\hline Wheels \\
\hline
\end{tabular}

\section{CONCLUSION}

After completing the project, we can conclude that our project is simple in construction and compact in size for use. Manufacturing of machine is easy and cost of the machine is less. As one can see, a micro resistance seam welder is a flexible machine that is well suited to fabricating various small-scale components. It offers a cost effective and high throughput joining method that often provides a reliable alternative to TIG and laser welding.

\section{REFERENCES}

[1] ISO 4063: "Welding and allied processes - Nomenclature of processes and reference numbers" (1998)

[2] "Welding Inspection Handbook", 3rd edition, American Welding Society, ISBN 0-87171-560-0, Miami, FL, pp. 10-11 (2000)

[3] Cary, Howard B. and Scott C. Helzer (2005). Modern Welding Technology. Upper Saddle River, New Jersey: Pearson Education. ISBN 0-13-113029-3.

[4] Lincoln Electric (1994). The Procedure Handbook of Arc Welding. Cleveland: Lincoln Electric. ISBN 99949-25-82-2.

[5] Welding Science and Technology by Md. Ibrahim Khan

[6] Manufacturing Science by Ghosh and Malik

[7] Modern Machining Process by Pandey and Shan. 